\title{
O DEBATE DAS QUESTÕES DE GÊNERO NA EDUCAÇÃO: UMA ANÁLISE DA POLÍTICA EDUCACIONAL BRASILEIRA
}

\author{
José Mauro de Oliveira Braz ${ }^{1}$ \\ Fernanda Santos Curcio ${ }^{2}$ \\ Lobelia da Silva Faceira ${ }^{3}$
}

\section{RESUMO}

O presente trabalho tem como objetivo problematizar a discussão de gênero na educação, mais especificamente, nos documentos que norteiam a política educacional brasileira, de maneira a compreender como tal questão vem sendo discutida e apresentada nos textos oficiais. Neste movimento, será possível examinar em que medida tais documentos promovem a discussão acerca da temática de gênero, refletindo, assim, aspectos inerentes aos seus avanços, limites e desafios. A título de metodologia, primeiramente, foi realizado um levantamento da documentação oficial acerca do sistema educacional brasileiro, tanto no âmbito da estruturação quanto no âmbito das recomendações de conteúdos a serem abordados nas disciplinas escolares. Posteriormente, por intermédio da perspectiva teórica da análise crítica, mapeou-se a utilização do

\footnotetext{
${ }^{1}$ Doutor (2020) e Mestre (2016) em Memória Social, Pedagogo com licenciatura plena (2014), tendo realizado Doutorado Sanduíche na Université Paris-Sorbonne - Paris IV (2018-2019). Atualmente é Assessor de Assuntos Legislativos da Secretaria de Estado de Educação do Rio de Janeiro e possuí ênfase de pesquisa nas áreas da educação em espaços não escolares; educação em prisões; violência, educação e comunicação; e, legislação educacional. ORCID: http://orcid.org/0000-0003-1075-2508. E-mail: jmobraz@yahoo.com.br

${ }^{2}$ Doutora em Memória Social pela Universidade Federal do Estado do Rio de Janeiro (UNIRIO). Professora e pesquisadora da Faculdade Metropolitana São Carlos. ORCID: http://orcid.org/0000-0001-8690-6492. E-mail: fernandasantoscurcio@gmail.com.

${ }^{3}$ Doutora em Educação pela Pontifícia Universidade Católica do Rio de Janeiro. Professora associada da Escola de Serviço Social e do Programa de Pós-Graduação em Memória Social (PPGMS), da Universidade Federal do Estado do Rio de Janeiro (UNIRIO). Líder do grupo de pesquisa "Violência, Prisão e Políticas Públicas" e da linha de pesquisa "Memória Social e Prisão: Reflexões sobre as políticas públicas no âmbito da execução penal". Bolsista Produtividade do CNPq. ORCID: http://orcid.org/0000-0002-7295-4909. E-mail lobeliasfaceira@yahoo.com.br
} 
termo "gênero" nestes documentos, a saber: a Lei de Diretrizes e Bases da Educação Nacional, os Parâmetros Curriculares Nacionais, os Novos Parâmetros Curriculares Nacionais, o Plano Nacional de Educação e a Base Nacional Comum Curricular. As conclusões apontam para o ainda tímido desenvolvimento do tema em âmbito escolar, principalmente em decorrência de conluios de grupos políticos que defendem moralmente a não divulgação científica dos conteúdos e discussões relativas à temática de gênero colocando-os de lado dentro de uma hierarquia do conhecimento, delegando-o a ser tratado em sala de aula somente quando for possível, ou então abordando essa (e tantas outras temáticas) em eventos culturais etc.

Palavras-chave: Gênero. Política Educacional. Política Pública.

\section{THE DEBATE ON GENDER ISSUES IN EDUCATION: AN ANALYSIS OF BRAZILIAN EDUCATIONAL POLICY}

\section{ABSTRACT}

The present work aims to problematize the discussion of gender in education, more specifically, in the documents that guide the Brazilian educational policy, in order to understand how this issue has been discussed and presented in the official texts. In this movement, it will be possible to examine the extent to which such documents promote the discussion on the theme of gender, thus reflecting aspects inherent to its advances, limits and challenges. As a methodology, firstly, a survey of the official documentation about the Brazilian educational system was carried out, both in terms of structuring and in terms of recommendations for content to be addressed in school subjects. Subsequently, through the theoretical perspective of critical analysis, the use of the term "gender" in these documents was mapped, namely: the Law of National Education Guidelines and Bases, the National Curriculum Parameters, the New National Curriculum Parameters, the Plan National Education and the Common National Curriculum Base. The conclusions point to the still timid development of the topic at school, mainly due to collusions of political groups that morally defend the non-scientific dissemination of the contents and discussions related to the gender 
theme, putting them aside within a hierarchy of knowledge, delegating it to be treated in the classroom only when possible, or else addressing this (and so many other topics) at cultural events, etc.

Keywords: Gender. Educational Policy. Public Policies.

\section{EL DEBATE SOBRE CUESTIONES DE GÉNERO EN LA EDUCACIÓN: UN ANÁLISIS DE LA POLÍTICA EDUCATIVA BRASILEÑA}

\section{RESUMEN}

El presnte trabajo tiene como objetivo problematizar la discusión de género en la educación, más específicamente, en los documentos que orientan la política educativa brasileña, para comprender cómo este tema ha sido discutido y presentado en los textos oficiales. En este movimiento se podrá examinar en qué medida dichos documentos promueven la discusión sobre el tema de género, reflejando así aspectos inherentes a sus avances, límites y desafíos. Como metodología, en primer lugar, se realizó un relevamiento de la documentación oficial sobre el sistema educativo brasileño, tanto en términos de estructuración como en términos de recomendaciones de contenidos a abordar en las asignaturas escolares. Posteriormente, a través de la perspectiva teórica del análisis crítico, se mapeó el uso del término "género" en estos documentos, a saber: la Ley de Lineamientos y Bases de la Educación Nacional, los Parámetros del Currículo Nacional, los Parámetros del Nuevo Currículo Nacional, el Plan Nacional de Educación y la Base Curricular Nacional Común. Las conclusiones apuntan al aún tímido desarrollo de la temática en el ámbito escolar, principalmente por connivencia de grupos políticos que defienden moralmente la difusión no científica de los contenidos y discusiones relacionados con la temática de género, dejándolos a un lado dentro de una jerarquía de saberes. , delegarlo para que sea tratado en el aula solo cuando sea posible, o bien abordar este (y tantos otros temas) en eventos culturales, etc.

Palabras clave: Género. Política Educativa. Política Pública. 


\section{INTRODUÇÃO}

Nos últimos anos, temos presenciado o afloramento da discussão sobre a inserção do debate de gênero nas escolas. Esse assunto tem se alastrado e gerado diversas discussões acerca do currículo escolar, que, por vezes, acabam sendo controversas e acaloradas. O Plano Nacional de Educação (PNE), aprovado no ano de 2014, documento que define metas da Educação Básica ao Ensino Superior, incluindo aspectos de gestão, para os próximos 10 anos, apresentou como proposta a discussão sobre a discriminação, equidade de gênero e orientações pedagógicas sobre a sexualidade.

Diante de tal fato, grupos de ativistas religiosos e parlamentares vêm se organizando e atacando firmemente tais apontamentos para adição de conteúdos desde que eles foram incorporados ao Plano. Isso sempre é feito por intermédio de discursos fundamentados em "achismos" e doutrinas religiosas, atrasando com isso, a possibilidade de implementação de importantes propostas pedagógicas que buscam a construção de uma sociedade mais coesa e equânime. Diante de tal conjuntura, Planos Estaduais e Planos Municipais de Educação, que possuem o mesmo espírito do $\mathrm{PNE}$, foram drasticamente alterados para serem aprovados sem conter textos relativos à temática do gênero e sexualidade, ou, contendo-os de forma tímida e marginal.

A justificativa para tanto é que tais temas e propostas são oriundos da suposta "ideologia de gênero". Esta "ideologia" atuaria com o objetivo de converter as crianças e adolescentes à homossexualidade e auxiliar no rompimento dos valores e papeis tradicionais que cabem aos homens e mulheres (MUNDIM, 2015). Contudo, o que se pode constatar é que se trata de uma discussão altamente relevante, diante da persistente discriminação, violência doméstica e violência sexual que marcam o cotidiano das mulheres, juntamente com as agressões, brutalidades e assassinatos da população LGBTQIA+. Parte-se do princípio de que qualquer discussão que venha a auxiliar no entendimento acerca da singularidade de cada ser humano é benéfica à sociedade. No entanto, por meio de um discurso ínscio, ou até mesmo farsante, parlamentares conservadores e ativistas religiosos rechaçam 
qualquer tentativa de construir a igualdade em seus âmbitos de atuação.

O gênero é apresentado como uma estrutura dada, natural, isenta de indagações e questionamentos. Isso impede que a construção do conhecimento acerca desse assunto apresente-se como crítica. Dessa forma, pretende-se problematizar a discussão de gênero na educação, mais especificamente nos documentos que constituem a política educacional brasileira, de maneira a compreender como tal problemática vem sendo discutida e apresentada nos textos oficiais. Aproveitamos para sinalizar que estamos tomando o gênero e suas expressões como produtos culturais, rompendo com os binarismos, compreendendo que pessoas podem lançar mão de atributos que vão além do feminino, masculino ou andrógino.

A título de metodologia, foi realizado um levantamento da documentação oficial que norteia as políticas do sistema educacional brasileiro, tanto no espaço da estruturação quanto no âmbito das recomendações de conteúdos a serem abordados nas disciplinas escolares. Posteriormente, por intermédio da análise de conteúdo, mapeou-se a utilização do termo "gênero" nestes documentos, a saber: a Lei de Diretrizes e Bases da Educação Nacional (1996), os Parâmetros Curriculares Nacionais (1997 e 1998), os Novos Parâmetros Curriculares Nacionais (2006), o Plano Nacional de Educação (2014) e a Base Nacional Comum Curricular (2017). O que se pretende é analisar como se dá a abordagem do tema ora proposto na política educacional brasileira, não sem antes discorrer sobre o conceito e a discussão de gênero de forma que se possa depreender o necessário para adentrar ao âmbito educacional.

\section{QUESTÕES DE GÊNERO: breves apontamentos}

O conceito de gênero, utilizado pela crítica feminista nos Estados Unidos na década de 1970, não é uma criação do movimento feminista. Antes de adequar-se à formulação de demandas de igualdade entre os sexos, o termo gênero foi elaborado inicialmente como componente de um discurso médico 
destinado às questões de problemas teórico-empíricos referentes ao diagnóstico e a terapêutica de pessoas hermafroditas (CARVALHO, 2011).

A princípio, o termo gênero foi apropriado por psicólogos na década de 1960 para denominar uma "identidade de gênero" junto a um corpo. Um deles é John Money, que estudava e buscava entender as pessoas que apresentavam no mesmo corpo atributos tidos como do sexo feminino e do sexo masculino. A partir desta realidade, suas "identidades de gênero" não poderiam ser produtos naturais de características corporais. Surge, nesse contexto, a dicotomia entre o conceito de sexo, enquanto algo corpóreo e natural, e gênero, ligado a cultura e ao comportamento (CARVALHO, 2011).

Um dos destaques trabalhado em torno do conceito de gênero é aquele que se desenvolve nas discussões das estudiosas Gayle Rubin (1975) e Joan Scott (1995). A primeira publica um trabalho em 1975 no qual reflete sobre a habitual opressão e subordinação das mulheres na sociedade a partir de um diálogo crítico com a teoria antropológica de Lévy-Strauss, com o marxismo e a psicanálise freudiana. A autora aponta que o gênero é uma divisão socialmente produzida e imposta nas relações sociais da sexualidade, produzindo o que a autora qualifica de sistemas de sexo-gênero.

Soma-se a esse pensamento a perspectiva de Scott (1995), que apresenta uma reflexão que reprova a concepção iluminista do sujeito único universal que possui características biológicas ahistóricas que assentam a dominação masculina. Ela rejeita o caráter fixo e permanente da oposição binária, promovendo a sua historização e requerendo uma desconstrução dos termos da diferença sexual. Desta forma, o gênero, enquanto elemento que integra as relações sociais que constituem as diferenças concebidas entre os sexos, demanda quatro elementos relacionados entre si: 1) os símbolos culturais presentes numa sociedade; 2) os discursos normativos (jurídico, religioso, educativo, científico, etc.) que "expressam interpretações dos significados dos símbolos"; 3) as instituições sociais, a organização social e econômica, como por exemplo, a educação, o sistema político, trabalho etc; e, 4) as 
identidades subjetivas, "as formas pelas quais as identidades generificadas são substantivamente construídas" (SCOTT, 1995, p. 86).

Nas décadas de 1980 e 1990, a crítica feminista, em particular o feminismo pós-estruturalista, colocou em questão o sistema de pensamentos sobre o gênero, em especial à lógica dualista, que gira em torno de posições extremas como natureza e cultura, macho e fêmea, mal e bom, sexo e corpo etc. Com isso, passou-se a refletir acerca destas posições e compreender que estas, assim como o entendimento de sexo e corpo, são produtos da cultura e por consequência, historicamente construídos. A partir disso, se "aponta a imbricação entre corpo, sexo e gênero, inclusive postulando que não se concebe corpo nem sexo ou sexualidade sem gênero" (CARVALHO; RABAY, 2015, p. 121).

Neste ponto, é necessário apresentar um desdobramento das reflexões acerca do gênero na sociedade, expresso por intermédio da teoria queer, que se lança a questionar a normatividade heterossexual e aponta para a condição social transformadora dos corpos e da sexualidade, dando visibilidade aos gays, lésbicas, bissexuais, transexuais, travestis e tantos outros corpos que existem socialmente (BUTLER, 2003).

A incorporação destes debates na agenda educacional promove a reflexão sobre novas práticas de liberdade e reconhecimento das individualidades. As práticas de liberdade seriam novas formas de agir em relação ao mundo, não recriando outras relações de poder, mas despertando o cultivo de uma ética fundada na estética da existência, aumentando com isso a visibilidade a uma das proposições paradigmáticas dos movimentos feministas contemporâneos: a de que o privado também é político (FOUCAULT, 2013).

O gênero é, portanto, uma categoria de análise cultural, histórica e política, que revela relações de poder, possibilitando utilizá-la em termos de diferentes sistemas, associando-o com outras categorias, como classe, raça, etnia, entre outros. Nesse sentido, sua compreensão requer que o sujeito se faça homem e mulher num movimento constante e dinâmico, logo, ser homem e 
ser mulher não é algo acabado, mas sim construído ao longo do tempo, por intermédio de determinadas práticas sociais.

Ao analisarmos tal assunto, é de suma importância trazer as reflexões sobre o poder na sociedade. Todo poder é potencialmente produtivo, criativo, e não algo basicamente opressor. Posto isto, deve-se sempre considerar que: o poder não existe sem discurso; o poder requer a produção de verdades; as verdades produzem o efeito do poder; o poder não é hegemônico e homogêneo, isso significa que não é algo que pertence somente a alguém ou a determinado grupo; os sujeitos são efeitos do poder, constituindose como um tipo de centro de transmissão; o poder necessita de mecanismos sutis que coloquem em circulação um saber pois "o poder produz saber [...], não há relação de poder sem constituição correlata de um campo de saber, nem saber que não suponha e não constitua ao mesmo tempo relações de poder" (FOUCAULT, 2010, p.30). Tal sentença, que não é simples, tão pouco superficial, indica a complexa relação entre o conhecimento e o poder. O gênero, nesse sentido, funciona como um saber sobre as diferenças sexuais, logo, falar dessas diferenças e da forma como são construídas é falar de poder na sociedade.

Foi mencionado que a categoria gênero pode ser entendida como um conceito sobre as diferenças sexuais, que hierarquiza tais diferenças dentro de uma perspectiva engessada e dual (SCOTT, 1995). O saber

[...] é aquilo de que podemos falar em uma prática discursiva que se encontra assim especificada: o domínio constituído pelos diferentes objetos que irão adquirir ou não um status científico; [...] um saber é, também, o espaço em que o sujeito pode tomar posição para falar dos objetos de que se ocupa em seu discurso; [...] um saber é também o campo de coordenação e de subordinação dos enunciados em que os conceitos aparecem, se definem, se aplicam e se transformam; [...] finalmente, um saber se define por possibilidades de utilização e de apropriação oferecidas pelo discurso (FOUCAULT, 2013, p.220). 
Nesse sentido, o conhecimento não é intrínseco ao homem, e sim construído, cuja verdade não existe fora ou sem o poder, ela é produzida por ele. Sendo assim, a verdade é produto de um contexto, é histórica e sofre conflitos contínuos. Por isso, cada sociedade produz as suas verdades, diante de seus próprios discursos, sendo estes um conjunto de pensamentos provenientes de relações de poder entre os sujeitos, preservando e legitimando as ideologias.

Pensar a política educacional requer entender, dentro desta perspectiva, que a sua constituição é marcada por intensas correlações de força de diferentes grupos sociais. Alguns autores se dedicaram a compreender e examinar tal espaço considerando a interferência do discurso religioso, mais especificamente, da Igreja Católica (LIMA, 1978; MILAN, 1986). Contudo, nas últimas décadas, é pôde-se constatar a expansão da inserção de grupos evangélicos, principalmente pentecostais e neopentecostais, dentro do espaço político brasileiro e por consequência nas políticas públicas realizadas (FRESTON, 1993; ORO, 2003; PIERUCCI; PRANDI, 1996).

A força política de tais grupos faz com que a sua atuação não possa mais ser desconsiderada das análises políticas do país. É dado que, desde o início dos anos 2000, frentes políticas de caráter religioso ganharam espaço de manifestação e continuam no seu fortalecimento como frente conservadora e protetora de uma moralidade cristã tradicional (TREVISAN, 2013). Estes grupos bem articulados apresentam um forte poder político que acaba por interferir nos mais variados projetos como os relativos à temática do aborto, dos direitos civis da população LGBTQIA+, e de qualquer outro assunto que venha a divergir dos valores morais e tradicionais cristãos compartilhados pelos grupos políticos brasileiros. Acerca disso, cumpre ressaltar que aspectos acerca da conhecida Frente Parlamentar evangélica, que:

[...] abriga parlamentares de diferentes igrejas e de diferentes partidos que se unem em torno de temas de seu interesse, normalmente propostas de cunho moral, ou ainda quando há interesses institucionais de suas igrejas. Esses temas morais muitas vezes ultrapassam seus próprios interesses 
partidários. Além disso, a força política de mobilização das igrejas que os apoiam tem se mostrado crescente, envolvendo seus fiéis em manifestações como Marchas para Jesus, bem como marchas específicas contra projetos que entendem nocivos para a sociedade [...]. Todas essas manifestações só surtem algum tipo de efeito dentro do Congresso Nacional em razão da própria característica conservadora do Congresso como um todo, e da sociedade que o elege [...]. Essa atuação não tende a esmorecer. [...] seu projeto é de ir além, aumentando seu poder de influência na elaboração de políticas públicas, não somente para o segmento religioso que mobiliza, mas para a sociedade como um todo (TREVISAN, 2013, p. 51-52).

O interesse acadêmico aqui, não gira em torno de como tais grupos vêm atuando e atravancando a política brasileira, e, apesar de não ser o foco do trabalho, não há possibilidade de nos esquivarmos dessa abordagem.

No entanto, antes de refletir sobre qualquer assunto, principalmente considerando que o resultado da reflexão poderá gerar consequências na sociedade civil, é necessário ultrapassar o conhecimento superficial, do âmbito do senso comum, e investigar as relações de uma forma mais rigorosa (FOUCAULT, 2013). Em se tratando do objeto da nossa investigação, a política educacional brasileira, é necessário considerar as questões que são incognoscíveis numa análise apenas dos textos. Logo, dentro de tal perspectiva, é requerido investigarmos e observarmos as relações históricas, políticas e sociais que estão por trás dos documentos que foram analisados. É necessário estar atento às condições que fazem um discurso ser legitimado, uma vez que ele se funda em condições e concepções de mundo nas quais grupos ou sujeitos atuam para legitimá-lo conforme seus interesses. Nesse sentido, tem-se que:

Cada sociedade tem seu regime de verdade, sua "política geral" de verdade: isto é, os tipos de discurso que ela acolhe e faz funcionar como verdadeiros; os mecanismos e as instâncias que 
permitem distinguir os enunciados verdadeiros dos falsos, a maneira como se sanciona uns e outros; as técnicas e os procedimentos que são valorizados para a obtenção da verdade; o estatuto daqueles que têm o encargo de dizer o que funciona como verdadeiro (FOUCAULT, 1979, p.12).

Diante disso, é possível relacionarmos os discursos dos grupos como um mecanismo gerador de poder que atua na garantia de sua legitimidade. A questão é que, quanto mais disfarçada a luta de poder se faz, mais forte ela é; e com isso, adentremos ao campo da educação para perscrutar de que forma isso ocorre.

\section{A EDUCAÇÃO NO BRASIL E AS QUESTÕES DE GÊNERO: ANÁLISE E RESULTADOS}

No campo das pesquisas qualitativas, a opção por certos métodos e técnicas para a análise de dados, requer necessariamente, viabilizar um olhar multifacetado sobre a integralidade dos dados recolhidos, uma vez que se está diante de uma pluralidade de significados. Elegeu-se, nesta pesquisa, o exame de alguns documentos que entoaram e entoam a política educacional por meio do arcabouço teórico da análise crítica do discurso (ACD). Sobre esta última, tratamo-la como uma perspectiva teórica sobre a língua, possibilitando as análises linguísticas ou semióticas ajuntadas em reflexões mais amplas acerca do processo social. Esta perspectiva dá espaço para uma relação dialógica com outras teorias e métodos sociais, não somente por uma abordagem interdisciplinar, mas, também, transdisciplinar. A partir disso, poderíamos oportunamente pensar e estabelecer uma frutífera relação entre o objetivo desta proposta e a ACD (FAIRCLOUGH, 2008).

Uma política pública - fundada em legislações, regulamentos, normas e diretrizes - significa ação e não-ação intencional da autoridade pública diante de uma questão específica. Além disso, é um campo marcado por correlações de forças e 
estratégias de implementação (FACEIRA, 2009). Mais que isso, tais documentos são fundamentalmente:

[...] moduladores de práticas, mas não devem ser vistos como unilateralmente construídos, porque eles também resultam de um contexto sóciohistórico e envolvem discursos na sua composição. São textos que revelam parcialmente o universo em que se instauram e por isso a análise não deve ser reducionista a ponto de apenas observar-lhe as "marcas linguísticas", mas, principalmente, compreendê-las à luz de uma teoria que as interconecte com outros elementos da vida social dos envolvidos (LIMA, 2010, p. 116).

Inicialmente, tem-se a Lei de Diretrizes e bases da Educação Nacional (LDB) - Lei no 9.394 de 20 de dezembro de 1996 -, que estabelece as diretrizes e bases da educação em nível nacional. Esta lei tem por base o princípio do direito universal à educação, trazendo alguns avanços em relação à lei anterior que regulamentava o sistema de ensino. Apesar de ser a principal lei que rege a dinâmica estrutural do sistema educacional brasileiro, mencionando quais setores do poder público serão responsáveis por quais modalidades de ensino ${ }^{4}$, explicando as modalidades de ensino e falando em obrigatoriedade - ou não - relacionada ao período de estudo da população, ela não faz qualquer menção à importância de discussões sobre preconceito juntamente com questões de raça e gênero. $O$ que se examina são alguns pontos de assertivas sucintas, trazidas de maneira trivial e sem qualquer problematização.

A partir desta perspectiva, esta lei elege onze princípios e fins da educação nacional. Do total, apenas uma menciona o respeito à liberdade e à tolerância (art. $3^{\circ}$, inciso IV). Porém, não há

\footnotetext{
${ }^{4}$ Pode-se mencionar, por exemplo, que segundo a LDB, os municípios deverão dedicar-se a dar mais atenção à oferta do ensino fundamental, enquanto os Estados deverão priorizar a oferta do ensino médio; sempre em regime de colaboração entre as partes, ou seja, um pode apoiar o outro de qualquer forma viável na intenção de cumprir a proposta de oferta de educação a todos (BRASIL, 1996b).
} 
qualquer problematização acerca de que liberdade é essa e de tolerância a que e/ou a quem se está tratando.

Posteriormente, foram analisados os Parâmetros Curriculares Nacionais (PCNs), instituídos nos anos de 1997 e 1998, elaborados pelo Governo Federal, com a finalidade de orientar os educadores mediante a normatização de aspectos fundamentais pertinentes a cada disciplina. Os parâmetros são destinados às redes pública e privada de ensino, de acordo com o nível de escolaridade dos estudantes. Objetiva-se, a partir dele, garantir que todos os estudantes tenham acesso aos conhecimentos entendidos como necessários para o exercício da cidadania. Porém, cabe destacar que os PCNs não são manuais de ação objetivos, servindo na verdade como norteadores para que professores, coordenadores e diretores, possam pensar o currículo e a dinâmica dos espaços escolares, levando em conta as especificidades locais da comunidade escolar.

Diante de todo o levantamento feito nos PCNs, este trabalho selecionou as disciplinas nas quais houve alguma abordagem em torno das questões de gênero.

Os PNCs para a disciplina de Geografia estão divididos em dois segmentos: o do $6^{\circ}$ ao $9^{\circ}$ ano; e o do ensino médio. No primeiro bloco, surge uma articulação entre esta disciplina e os temas transversais (BRASIL, 1998e) ${ }^{5}$. Para o segmento fundamental, ao relacionar a geografia com o tema de orientação sexual, o documento, ainda que problematize timidamente os preconceitos e dificuldades que as mulheres enfrentam nas várias dimensões do cotidiano, como trabalho doméstico, maternidade, mercado de trabalho etc., não questiona e não aborda o binarismo feminino e masculino. Além disso, não menciona que os "papeis" dos homens e "papeis" das mulheres são fenômenos nada naturais, mas sim culturalmente construídos. Já naquele dedicado ao segundo segmento, a referida discussão é ainda mais incipiente. No texto destinado à disciplina de Geografia para o ensino médio não há qualquer menção acerca das questões de gênero. A Geografia, como apresenta, é uma ciência do presente, constituída na realidade contemporânea, que objetiva:

\footnotetext{
${ }^{5}$ Será abordado à posteriori.
} 
[...] contribuir para o entendimento do mundo atual, da apropriação dos lugares realizada pelos homens, pois é através da organização do espaço que eles dão sentido aos arranjos econômicos e aos valores sociais e culturais construídos historicamente (BRASIL, 1998a, p. 30).

Além disso, os parâmetros ainda salientam que o ensino da Geografia proporciona aos estudantes o reconhecimento das contradições e conflitos sociais, econômicos e culturais, permitindo, assim, contrapor e avaliar as relações sociais, hábitos, ações, formas de utilização e exploração de recursos e pessoas, no sentido de promover o respeito às diferenças, na busca de uma sociedade mais equânime.

Contudo, mesmo diante de tal assertiva, que abre espaço para uma discussão frutífera para as questões relacionadas às variadas formas das desigualdades sociais, o referido texto não reporta tal discussão, e muito menos, trata do gênero, mesmo que, embrionariamente, como no documento referente ao nível fundamental.

No que tange aos PNCs da disciplina de História direcionados ao segmento do $6^{\circ}$ ao $9^{\circ}$ ano, ao tratar dos critérios de seleção e organização da disciplina, o documento afirma que seus conteúdos deverão estar articulados com temas transversais com o objetivo de anteferir as diferenças étnicas, etárias, religiosas, culturais e de gênero. Tal movimento age no fortalecimento dos laços de identidade e no senso crítico sobre as consequências históricas das ações e comportamentos de discriminação e segregação. Além disso, as discussões deverão privilegiar, dentre outros aspectos,

[...] as imagens, representações e valores em relação ao corpo, à sexualidade, aos cuidados e embelezamento do indivíduo, aos tabus coletivos, à organização familiar, à educação sexual e à distribuição de papéis entre homens, mulheres, crianças e velhos nas diferentes sociedades historicamente constituídas (BRASIL, 1998b, p. 49). 
Nota-se, diante de tal afirmativa, uma preocupação em historicizar estes fenômenos, tirando-os de uma perspectiva naturalista da realidade. Não obstante, não há um aprofundamento desta discussão, tornando o discurso fragmentado e pontual. O texto não prossegue arguindo e/ou explicando tais temas, dificultando, assim, uma apreensão integralizada. Ainda convém apontar, a partir deste fragmento, a manutenção e reprodução da lógica binária a partir das "distribuições de papeis".

Este PNC também traz diversas problematizações sobre as figuras das mulheres, juntamente com crianças e idosos, em diversos contextos das relações sociais (como, por exemplo, as relações de trabalho), que podem e devem ser trabalhadas na disciplina de História. $\mathrm{O}$ documento ainda cita as diversas lutas entre grupos sociais que podem surgir como subtema de discussão pedagógica no eixo temático "História das representações e das relações de poder", porém um fato gerou certa inquietação: a não nomeação do movimento feminista, substituindo-o por "lutas de gênero" (BRASIL, 1998b, p. 68).

Em outra passagem, o documento fala sobre a importância de se discutir os direitos das mulheres no contexto mundial, contudo, não faz menção ao movimento feminista novamente. Compreende-se que falar sobre a conquista dos direitos civis e políticos das mulheres torna-se imperativo tratar do movimento feminista, desde o seu surgimento até a atualidade, pois foi a partir dele que as conquistas sociais diversas foram alcançadas.

Outra disciplina que também apresenta discussões de relações de gênero é a Arte. Nas orientações para o $6^{\circ}$ ao $9^{\circ}$ ano, a palavra gênero aparece algumas vezes, contudo, sem ser justificada. Apesar disso, os discursos são mais incisivos que nas disciplinas apresentadas anteriormente, ao propor a construção de conhecimento crítico em relação aos preconceitos e discriminações de gênero. $O$ caderno do PCN de Arte propõe que a disciplina busque uma

Reflexão, discussão e posicionamento crítico sobre a discriminação de gênero, etnia e minorias, na prática da interpretação e criação musicais em 
diferentes culturas e etnias, em diversos tempos históricos. (BRASIL, 1998c, p. 85).

Porém, é possível constatar ao longo das proposições, que as ideias ainda se baseiam no binarismo fixo e naturalizado, cravando de um lado o masculino, e, de outro o feminino. Tal ideia fica evidente na seguinte passagem:

compreender a organização dos papéis sociais em relação aos gêneros (masculino e feminino) e contextos específicos como etnias, diferenças culturais, de costumes e crenças, para a construção da linguagem teatral. (BRASIL, 1998c, p. 86).

Embora ocorra o entendimento das interferências conjunturais que fundamentam a organização social e as relações sociais, os gêneros ainda são tratados como polos opostos e inquestionáveis. No documento que norteia as ações no Ensino Médio, não há discussões e apontamentos em relação às questões de gênero. Tal fato era inesperado nesta pesquisa, pois o campo da Arte se forma, a partir do conhecimento constituído no âmbito sensível-cognitivo, aberto a variados significados, sensibilidades, modos de criação e espaços fortemente ligados ao mundo cultural, cenário altamente propício para tais problematizações.

Ao se analisar os PNCs da Educação Física no Ensino Fundamental, nota-se que há uma maior preocupação em tratar dos preconceitos e estereótipos de gênero. No que se refere às relações do corpo e da motricidade, o referido documento aponta que há uma questão presente

[...] no universo da cultura corporal de movimento e da sexualidade que diz respeito à configuração de padrões de gênero homem e mulher e sua relação com o corpo e a motricidade, padrões que se constroem e que são cultivados desde a infância, pautados em referências biológicas e socioculturais. Essa construção pode ser compreendida pela explicitação das atitudes cotidianas, muitas vezes inconscientes e automáticas, pautadas em valores preconceituosos. Por exemplo, com relação à habilidade das 
meninas para jogar futebol, é comum surgirem frases como: "ela joga bem, parece até homem jogando, [...] nesses casos, é fundamental que se questione o modelo de eficiência que tem como referência o jogo masculino. Essa visão em si já está permeada de valores culturais e estabelece padrões de identificação para a caracterização de gênero em relação com a motricidade, pois as características mais genéricas da motricidade do gênero masculino, como força e velocidade, e do gênero feminino, como coordenação e equilíbrio, devem ser compreendidas independentemente do valor que socialmente se atribui a elas (BRASIL, 1998d, p. 41-42).

Observando a citação acima, verifica-se que há uma relevante problematização acerca dos preconceitos e estereótipos de gênero, que marcam as relações sociais, especificamente no âmbito da prática esportiva. Constata-se também que há um movimento de historicizar tais padrões, colocando-os como não naturais, mas sim produtos socioculturais.

Ao longo dos PNCs da Educação Física, ainda foram verificados outros apontamentos sobre o tema: indicação da discussão crítica sobre a inclusão e exclusão das mulheres em determinados esportes e em certos momentos históricos; proposição de realização de aulas mistas de Educação Física para oportunizar a convivência e o respeito à diferença entre meninos e meninas, no sentido de "não reproduzir, de forma estereotipada, relações sociais autoritárias" (BRASIL, 1998d, p. 42); afirmação da importância de uma reflexão e problematização dos docentes sobre os valores e conceitos, mantidos implicitamente, que inserem e reforçam relações de submissão no espaço escolar, relacionado as questões de gênero.

No documento referente ao Ensino Médio, não está presente qualquer discussão que caminhe neste sentido, havendo apenas uma breve e dispersa proposição de "respeito às diferenças".

Outros textos analisados foram aqueles que compunham os Novos Parâmetros Curriculares do Ensino Médio ( $\mathrm{PCN}+$ ), lançados no ano 2006, no contexto de reforma e implantação do Novo Ensino 
Médio. O tratamento da temática em pauta ganha mais espaço que na versão anterior, que tratava dos parâmetros para o ensino médio, contudo, ainda se mantém uma abordagem despretensiosa.

No que tange a disciplina de Educação Física, diferentemente do relativo avanço no trato realizado nos PCNs do Ensino Fundamental de 1998 - que não ocorreu no documento referente ao Ensino Médio -, o atual texto aponta: "são inegáveis as muitas diferenças no comportamento de meninos e meninas. Reconhecê-las e trabalhar para não as transformar em desvantagens é papel de todo educador" (BRASIL, 2006a, p. 76). Um avanço a se considerar é o fato de o material demandar a não utilização e atitudes e piadas sexistas, ou seja, a orientação aponta o professor também como responsável pela disseminação da cultura machista e excludente.

Nos parâmetros para a disciplina de Arte consta apenas uma passagem que cita o termo "preconceito de gênero", junto das questões de etnia, faixa etária, origem social etc., apontando que devem ter espaço nas manifestações artísticas e estéticas, pois estas são consideradas práticas modernas e contemporâneas de "humanização e aproximação entre pessoas e povos" (BRASIL, 2006c, p. 191).

Na disciplina de História, por sua vez, há igualmente apenas uma menção, apontando que a disciplina deverá incorporar "problemáticas e anseios individuais, de classes, de gêneros, de grupos sociais, locais, regionais, nacionais e mundiais, que projetam a cidadania enquanto prática e enquanto realidade histórica" (BRASIL, 2006a, p. 78). Compreende-se que a disciplina de História pode e deve atuar no sentido de possibilitar o surgimento de vozes de grupos antes silenciados, no entanto, percebe-se novamente um retrocesso em relação à tímida discussão presente nos PNCs da referida disciplina no âmbito do ensino fundamental. Não há, neste momento, qualquer debate ou problematização acerca das questões de gênero, apenas uma breve indicação.

Por fim, os parâmetros para Biologia reproduzem um discurso puramente biológico tanto no que tange às questões de gênero como de sexualidade. Como discussão e argumentação de temas de interesse de ciência e tecnologia torna-se fundamental 
[...] analisar de que maneira textos didáticos, revistas, jornais, programas de tevê e rádio tratam questões relativas à sexualidade como as questões de gênero, as expressões da sexualidade, as relações amorosas entre jovens, as doenças sexualmente transmissíveis, distinguindo um posicionamento isento, bem fundamentado do ponto de vista científico, da simples especulação, do puro preconceito ou de tabus (BRASIL, 2006b, p. 38).

Nesse texto não há qualquer discussão acerca da dinâmica sociocultural na constituição e fundamentação do gênero. Logo, este é considerado natural e não um produto das relações sociais.

Todos os cadernos dos PCNs foram sistematicamente abordados, sempre evidenciando aqueles que apresentavam conteúdo a ser compartilhado. No entanto, merecem destaques os cadernos de temas transversais. São eles: Pluralidade Cultural; Meio Ambiente; Saúde; Orientação Sexual.

Os temas transversais são assim nomeados por não pertencerem a nenhuma disciplina específica, mas atravessam todas elas como se a todas fossem pertinentes. Constituem-se na prática como um manual de orientação para abordagem de determinados conteúdos que, não obrigatoriamente, devem estar presentes nas escolas e disciplinas. Tratam-se assim de propostas nas quais as secretarias e as unidades escolares poderão se basear para elaborar seus próprios planos de ensino.

Especificamente, acerca do caderno de orientação sexual, que é aquele que, a priori, dialoga com a temática desta investigação, tem-se postulado que se deve:

[...] considerar a sexualidade como algo inerente à vida e à saúde, que se expressa no ser humano, do nascimento até a morte. Relaciona-se com o direito ao prazer e ao exercício da sexualidade com responsabilidade. Engloba as relações de gênero, o respeito a si mesmo e ao outro e à diversidade de crenças, valores e expressões culturais existentes numa sociedade democrática e pluralista. Inclui a importância da prevenção das doenças 
sexualmente transmissíveis/Aids e da gravidez indesejada na adolescência, entre outras questões polêmicas. Pretende contribuir para a superação de tabus e preconceitos ainda arraigados no contexto sociocultural brasileiro (BRASIL, 1998e, p. 287).

Diferentemente dos outros documentos, este apresenta uma discussão mais detalhada e reflexiva sobre o gênero, entendendo-o como algo construído, fundamentado em padrões socialmente estabelecidos como feminino e masculino. Tais padrões, como aponta, são produtos de representações sociais e culturais edificadas a partir das diferenças biológicas dos sexos, e o material, ainda que não questione o binarismo, traz diversos avanços não contidos nos demais documentos. O discurso pontual ou indefinido dos outros parâmetros, não traz problematizações críticas acerca dos estereótipos e papeis de gênero, homossexualidade, bissexualidade, novos lugares políticos e econômicos ocupados por mulheres, mudanças na esfera doméstica e reconhecimento do movimento feminista.

Outro documento analisado é a Lei 13.005 de 25 de junho de 2014 que aprova o PNE, vigente para os próximos 10 anos. A construção do referido documento gerou uma série de polêmicas, e uma delas interessa a este trabalho. Antes de sua aprovação, o Senado alterou o inciso III do Artigo $2^{\circ}$ que diz respeito à alteração da diretriz que anunciava a superação das desigualdades educacionais: promoção da "igualdade racial, regional, de gênero e de orientação sexual", expressão substituída por "cidadania e na erradicação de todas as formas de discriminação".

É importante esclarecer que não há no Plano Nacional uma cláusula vinculante em relação às discussões dos planos estaduais e municipais, logo, não é impeditivo que estados e municípios tratem de diferentes temas em seus respectivos planos. Porém, tal substituição é um retrocesso se comparada com os parâmetros apresentados anteriormente que datam da década de 1990. Além disso, é fundamental compreender o intenso jogo político que atravessa tal realidade. Pôde-se verificar como os debates em torno da temática de gênero e sexualidade geram movimentação na mídia, em decorrência do posicionamento de caráter 
preconceituoso que a parte que defendia a retirada dessa discussão do plano tomou (PIOVEZAN, 2015). Isso obviamente ressoou nos planos municipais e estaduais de educação, comprometendo toda uma estrutura de planejamento político de âmbito educacional que já estava há muito traçada. Junto das movimentações em comissões havia também projetos de lei, dos quais destacamos o projeto 2731/2015, que além de alterar o Plano Nacional de Educação, proibindo a discussão de gênero dentro dos espaços escolares, prevê também, pena de prisão para os professores que desrespeitem a determinação; e o projeto 7180/2014, que intenciona alterar a LDB, por intermédio da modificação do inciso XIII do artigo $3^{\circ}$ - que tem como um dos princípios do ensino "pluralismo de ideias e de concepções pedagógicas" - para proibir o ensino daquilo que chama de "ideologia de gênero". Tais projetos, contudo, contrariam os princípios da educação brasileira previstos na Constituição Federal que prevê a "liberdade de aprender, ensinar, pesquisar e divulgar o pensamento, a arte e o saber, bem como o pluralismo de ideias e concepções pedagógicas".

Outro destaque no que tange a não contemplação da temática em âmbito nacional é a última versão da Base Nacional Comum Curricular lançada no ano de 2017, que não faz qualquer menção às questões de gênero (a palavra nem ao menos é citada no texto, aparecendo apenas no sentido de gêneros textuais) e homofobia.

É pertinente, aqui, abordarmos a noção de interdição (FOUCAULT, 2010), que se manifesta pelo "direito de dizer tudo, que não se pode falar de tudo em qualquer circunstância" (p. 9). Para tanto, o discurso se dispõe a partir do princípio de exclusão, arrojado pelo exterior, por meio do processo de interdição, empreendendo os acontecimentos de ocorrência contingente. Seguindo tal entendimento, e partindo das contribuições de Revel (2005) e Cabral (2013, p. 9), que postulam o discurso como um:

[...] conjunto de enunciados que dependem da mesma formação discursiva e que se inscreve em um dado campo, não fugiria dessa força regulatória. Como uma forma de restrição de um campo, a interdição está relacionada àquilo que 
determina o que se pode falar, e a partir de que lugar: se, de um lado, o discurso se constitui a partir do que pode e do que deve ser dito; de outro, ele também engendra meios para excluir. É própria a um período particular, e possui função normativa e reguladora, colocando em funcionamento mecanismos de organização do real por meio da produção de saberes, de estratégias e de práticas vigentes em determinadas épocas.

Isto posto, é importante evidenciar que "qualquer sistema de educação é uma forma política de manutenção ou modificação da apropriação de discursos e dos conhecimentos e poderes que eles carregam" (FAIRCLOUGH, 2008, p. 123). Logo, tal espaço deve ser visto e compreendido como uma manifestação política de poder. Não são poucos e fáceis os embates constituídos no campo educacional, pois como aponta Louro (1995, p. 124).

[...] sendo a instituição escolar, tal como hoje a conhecemos, tributária dessas duas outras instituições [Igreja e Estado], ela também irá atuar (como as anteriores) no processo de "individualização dos sujeitos", desenvolvendo formas de exercício de poder assemelhadas, articuladas ou referidas às da Igreja e do Estado.

Importa, então, pensar as nuances e implicações das transformações que entoam o discurso da política educacional no movimento de interdição e censura do debate de gênero. Tal movimento empreende ações que podem caminhar para a tentativa de silenciamento e esquecimento das mesmas. Fortes são os entrelaçamentos que compõem este jogo, elementos são censurados, excluídos e ocultados. Tal naturalização, que pode vir a marcar o esquecer do esquecido, constrói os fatos como herança acabada e esconde o devir fundador do fazer social, em que o tempo deixa "de ser encarado em sua permanente alteridade e passa a ser visto como caminho na direção do homogêneo, do idêntico, da mesmicidade" (GONDAR, 2000, p. 38). 
Não é possível, nesta oportunidade, oferecermos uma análise rigorosa deste panorama, mas, a partir desta breve exposição, foi possível propormos o levante de algumas questões e indagações que servirão como norteadores de pesquisas futuras. Compreendendo que as estruturas discursivas estão interrelacionadas com as práticas sociais, indicando, assim, a relação entre discurso e poder, é factual que as instituições exerçam através (também) da escrita de textos - a conservação e amoldamento de práticas coercitivas e ajustadoras de comportamentos. As palavras - sua permanência ou ausência conformam sentidos e significados que dizem respeito ao contexto social e político do cenário ora estudado.

O que visualizamos é que os discursos que atravessam o meio social têm conformado a política educacional, alastrando-se, vestindo a armadura da "verdade", fazendo com que os sujeitos ali presentes obedeçam ao status quo. Contudo, é impreterível que se questione e que se coloque em xeque tais configurações, tratando e ratificando a educação como um espaço político que deve caminhar no sentido de promoção da autonomia, da liberdade e do respeito.

\section{CONSIDERAÇÕES FINAIS}

Diante das reflexões levantadas ao longo deste trabalho, é possível visualizarmos a complexidade que marca o assunto ora proposto. Analisar e compreender o ordenamento social requer considerar o conjunto de instituições que formam a sociedade, uma vez que possuem como característica principal a sua condição de reprodução. Tais espaços, enquanto sistemas de saber-poder, reproduzem memórias necessárias à sua manutenção, possuindo um conjunto de regras e procedimentos padronizados socialmente. A importância das instituições concretiza-se no fato destas possuírem a capacidade de conservar a organização social e satisfazer as necessidades de determinados grupos que as compõem. São, portanto, instâncias conservadoras a priori e atuam com a intenção de manter a ordem social. O que nos importa questionar é: Que tipo de ordem? Qual é a sua natureza? Para que e para quem - ela serve? Como ela se tornou legítima? Quais 
memórias foram construídas para a sua reprodução? Quais memórias foram esquecidas para que ela se mantenha? Quais discursos foram incansavelmente repetidos para afirmar a sua potência? $E$, quais discursos foram silenciados e violentamente manipulados?

A manutenção de uma ordem e de um discurso necessita de um processo ininterrupto de repetição. Para tanto, é impreterível que se questione e que se coloquem em xeque tais configurações, tratando e ratificando a educação como um espaço político que deve caminhar no sentido de promoção da autonomia, da liberdade e do respeito. Em tal movimento, é possível vislumbrar formas e processos de liberdade, pois, se num primeiro momento a memória se afirma como um instrumento de poder, ulteriormente, mostra-se, também, como uma arma que dá forma ao novo. Surge, neste momento, a imprescindibilidade de se remeter ao campo da memória, pois esta sofre um eterno processo de construção e transformação, têm seus conflitos, disputas e embates, estando sempre passível a produzir atos transformadores e criativos.

Diante desta discussão verifica-se que a construção do conhecimento relativo à questão de gênero, frente à sociedade brasileira, é complexa, mas possível, necessitando de mais estudos e pesquisas. Logo, frente ao que pôde ser observado no decorrer do trabalho, serão trazidas mais conjecturas e possibilidades do que afirmativas e certezas.

Apesar de a transdisciplinaridade ser um dos termos muito explorados em alguns setores da educação, os documentos que orientam as práticas e planejamentos curriculares não o fazem, e com isso consequentemente as dinâmicas escolares, desde as aulas até os projetos da escola, não se apropriam disso. Disto, tem-se que os cadernos disciplinares não se preocupam em abordar tais temas, dentre eles, as temáticas de gênero.

O fato é que a disciplinarização dos conteúdos escolares não contribui para a abordagem das amplas questões relativas à sociedade e suas dinâmicas. Essa "grade disciplinar" faz com que as escolas se utilizem de subterfúgios pedagógicos, a fim de dizerem que cumprem um papel democrático, enquanto possuem setores de estudo disciplinar intensivo, objetivando manter suas altas taxas de 
avaliação externa e índice de empregabilidade/aprovação em vestibular de seus estudantes egressos.

Deve-se relembrar que partimos da premissa de que o afloramento de uma cidadania ativa por parte dos estudantes requer uma educação permanente que ultrapasse o dia a dia da escola, e que busque compreender as dificuldades e interesses destes sujeitos frente às dinâmicas sociais. As práticas educativas devem ser guiadas no sentido de provocar ao ser humano, a vontade de desvendamento do mundo, para que assim, se perceba como sujeito capaz de atuar neste mundo e transformá-lo, pois é por intermédio do processo educativo que o estudante assimila atitudes, valores sociais, morais e políticos. Portanto, é importante que haja uma transformação substancial e desafiadora de como vemos e percebemos a educação nas escolas, principalmente no que tange a temática aqui abordada. Longe de ser um instrumento para adequar e habituar os sujeitos ao ambiente e normas da sociedade, a escola deverá promover a formação da ação racional, reflexiva e crítica, e auxiliar no desenvolvimento pessoal e criativo de todos os que por ela passam.

\section{REFERÊNCIAS}

BRASIL. Lei no 13.500, de 25 de junho de 2014. Aprova o Plano Nacional de Educação - PNE e dá outras providências. Brasília, DF: Centro Gráfico, 1996a.

BRASIL. Lei n. 9.394 de 20 de dezembro de 1996. Estabelece as diretrizes e bases da educação nacional. Brasília, DF: Centro Gráfico, 1996b.

BRASIL. Ministério da Educação. Base Nacional Comum Curricular - BNCC. Brasília, DF, 2017.

BRASIL. Orientações curriculares complementares aos parâmetros curriculares nacionais $(\mathbf{P C N}+)$ : Ciências humanas e suas tecnologias. Brasília: MEC, 2006 a. 
BRASIL. Orientações curriculares complementares aos parâmetros curriculares nacionais ( $\mathrm{PCN}+)$ : Ciências da natureza e matemática e suas tecnologias. Brasília: MEC, 2006b.

BRASIL. Orientações curriculares complementares aos parâmetros curriculares nacionais ( $(\mathbf{C N}+)$ : Linguagens, códigos e suas tecnologias. Brasília: MEC, 2006c.

BRASIL. Parâmetros curriculares nacionais: apresentação dos temas transversais. Brasília: MEC, 1998e.

BRASIL. Parâmetros curriculares nacionais: artes. Brasília: MEC, 1998C.

BRASIL. Parâmetros curriculares nacionais: educação física. Brasília: MEC, 1998d.

BRASIL. Parâmetros curriculares nacionais: geografia. Brasília: MEC, 1998a.

BRASIL. Parâmetros curriculares nacionais: história. Brasília: MEC, 1998b.

BRASIL. Projeto de lei 2731. Altera a Lei no 13.005, de 25 de junho de 2014, que estabelece o Plano Nacional de Educação - PNE e dá outras providências. Brasília, DF: Câmara dos Deputados, 2015.

BRASIL. Projeto de lei 7180. Altera o art. $3^{\circ}$ da Lei no 9.394, de 20 de dezembro de 1996. Brasília, DF: Câmara dos Deputados, 2014.

BUTLER, J. Problemas de gênero: feminismo e subversão da identidade. Rio de Janeiro: Civilização Brasileira, 2003.

CABRAL, L. Parece mas não é: considerações sobre o efeito de verdade no gênero editorial. BOCC. Biblioteca Online de Ciências da Comunicação, v. 10, p. 1-21, 2013.

CARVALHO, M. E. P.; RABAY, G. Usos e incompreensões do conceito de gênero no discurso educacional no Brasil. In: Revista de Estudos Feministas, v. 23, p. 119-136, 2015.

CARVALHO, M. O conceito de gênero: uma leitura com base nos trabalhos do GT Sociologia da Educação da ANPEd (1999-2009).

Revista Brasileira de Educação, v.16, 2011. 
FACEIRA, L. O ProUni como política pública em suas instâncias macro-estruturais, meso-institucionais e microssociais: Pesquisa sobre a sua implementação pelo MEC e por duas Universidades na Região Metropolitana do Rio. Rio de Janeiro, 2009. Tese (Doutorado em Educação) - Pontifícia Universidade Católica-Rio. Rio de Janeiro, 2009.

FAIRCLOUGH, N. Discurso e Mudança Social. Brasília: Editora Universidade de Brasília, 2008.

FOUCAULT, M. A ordem do discurso. São Paulo: Editora Loyola, 2010.

FOUCAULT, M. Microfísica do poder. Rio de Janeiro: Graal, 1979.

FOUCAULT, M. A Arqueologia do saber. Rio de Janeiro: Forense Universitária, 2013.

FRESTON, P. Protestante e Política no Brasil: Da Constituinte ao Impeachment. Unicamp, 1993.

GONDAR, J. Lembrar e esquecer: desejo de memória. In: COSTA, Iclea.; GONDAR, Josaida. (Org.) Memória e espaço. Rio de Janeiro: 7 Letras, 2000.

LIMA, A. M. Uma análise crítica dos documentos oficiais que prescrevem o trabalho do professor. Revista do GELNE, Piauí, n.1/2, p. 115-126, 2010.

LIMA, D. Educação, Igreja e ideologia: uma análise sociológica da elaboração da Lei de Diretrizes e Bases. Rio de Janeiro: F. ALVES, 1978.

LOURO, G. Gênero, História e Educação: Construção e Desconstrução. Revista Educação e Realidade, v. 20, 1995.

MILAN, Y. M. N. O reacionarismo católico e a educação como ação. 1986. 131 p. Dissertação (Mestrado em História e Filosofia da Educação). Faculdade de Educação. Universidade Estadual de Campinas, UNICAMP. São Paulo, 1986.

MUNDIM, I. O que é a ideologia de gênero que foi banida dos planos de educação afinal? São Paulo, 2015. Disponível em: 
https://educacao.uol.com.br/noticias/2015/08/11/o-que-e-aideologia-de-genero-que-foi-banida-dos-planos-de-educacaoafinal.htm>. Acesso em 04 de agosto de 2019.

ORO, A. P. A política da Igreja Universal e seus reflexos nos campos religioso e político brasileiros. Revista Brasileira de Ciências Sociais, v. 18, p. 53-69, 2003.

PIERUCCI, A. F.; PRANDI, R. A realidade social das religiões no Brasil, São Paulo: Hucitec, 1996.

PIOVEZAN, S. Metas para área da Educação ignoram questões de gênero e geram polêmica. São Paulo, 2015. Disponível em:

<http://g1.globo.com/sp/sao-carlos-regiao/noticia/2015/06/metaspara-area-da-educacao-ignoram-questoes-de-genero-e-gerampolemica.html>. Acesso em 04 de agosto de 2019.

REVEL, J. Michel Foucault: conceitos essenciais. São Paulo: Claraluz, 2005.

RUBIN, G. The Traffic in Women: Notes on the 'Political Economy' of Sex. In: REITER, R. (Org.). Toward na Anthropology of Women.

New York and London: Monthly Review Press, 1975.

SCOTT, J. W. Gênero: uma categoria útil de análise histórica. Revista Educação e Realidade. Porto Alegre, v. 20, 1995.

TREVISAN, J. A Frente Parlamentar Evangélica: Força política no estado laico brasileiro. Numen: Revista de Estudos e Pesquisa da Religião, Juiz de Fora, v. 16, n. 1, p. 581-609, 2013.

\section{Submetido em:}

Aceito em: 